\title{
HIGH TECH / LOW TECH: TECTONIC MACHINES, EARTH-BUILT TRADITIONS, AND CONSTRUCTING THE EXIGENT CITY
}

\author{
Marcus Shaffer* \\ Department of Architecture, The Pennsylvania State University, USA \\ *Corresponding author(marcus@psu.edu)
}

\begin{abstract}
With continuous advancements in the performance and economics of mobile/remote technologies and computer-aided manufacturing (CAM) systems comes an increase in the plausibility of semi-autonomous construction devices for deployment in response to large-scale humanitarian disasters. Robotic building-making machines capable of continuously and safely erecting replacement housing, urbanistic architecture required for resettlement economies, and semi-permanent "emergency cities", represent our enormous technological potential to better the lives of people currently living in Refugee/Internally Displaced Person (IDP) status around the world (estimates range from 33 to 175 million people). In addition to producing homes and marketplaces, these Tectonic Machines act as digital-mechanical extensions of our human sensibilities with regards to architecture. They must be designed to address the cultural and communal alienation of displaced populations through extreme accommodation in systematically producing a variety of vernacular building types using traditional/local materials. This paper will report on the development of a specific type/model of Tectonic Machine being designed for disaster preparedness and response. The Shokushu Machines are mobile, robotically variable formwork/falsework for use in 'molding' buildings, specifically where low-tech/no-fire ceramic construction traditions (such as cast earth or sun-baked mud) coincide with large-scale humanitarian relief operations. Globally, this is a geographic operations area that includes Mexico and Central America, Africa, the Middle East, and South Asia. Currently, the world's largest IDP camp--located in Northern Kenya--holds 290,000 displaced people in a $50 \mathrm{sq}$ km environment entirely handbuilt of mud. Challenges include: cultural adaptation and technological systems interface, maneuverability, autoconfiguration, and renewable power sources.
\end{abstract}

Keywords: Tectonic Machines, Displacement Environments, Earth-built Traditions, Exigent Cities

\section{INTRODUCTION: PROFILE OF A REFUGEE}

In Asia-especially in Japan-the historical development of automated/robotic construction machinery has been motivated by four factors: labor substitution in response to shifting demographics (aging), a desire to contain or eliminate hazardous working conditions in construction environments, a desire for greater efficiency and quality control in construction product, and a desire to lessen or alleviate the ecological impact of construction related processes [1]. If we turn the measure of these factors away from socially stable environments with commercial motivations and point them at humanitarian conditions as described in current refugee/IDP demographic information
[2] published by the Office of the United Nations High Commission for Refugees (UNHCR), the potential application for automated/robotic construction devices is an obvious one. People forced to live in displacement environments-and construction-related professionals who desire to aid them but are limited by geographic dislocation or hazardous environments-might mutually benefit through technological mediation in the form of deployable and semi-autonomous construction machines (Tectonic Machines) [3]. The shifting environmental conditions of refugee accommodation and an essential role for automated/robotic construction machinery emerge in two especially significant statistics from UNHCR 
documentation:

1. For the first time (in 2007) cities, not camps are harboring greater populations of persons displaced by warfare, famine, natural disasters and economic crisis. With wars concentrated around urban areas such as Bagdad, and natural disasters striking urban coastal areas (New Orleans, Sendai), the numbers of urbanite refugees and refugees displaced into urban areas continue to increase. According to the published data, 85 percent of this urbanbased refugee population is in Asia and the Middle East [4]. 2. When we talk about refugees and displaced persons, we are now predominately talking about women and children [5]. This means that displacement accommodations and environments are being built for-and often by-people who would typically be excluded from construction industries or from working in commercial construction environments. Additionally, these populations are prone to be effected by injury and physical exhaustion from violence, forced travel, malnutrition, and/or extreme weather conditions. These problems obviously have the potential to effect one's ability to construct.

\section{ENVIRONMENTAL PROFILE: MUD CITIES}

If the contemporary refugee population can be characterized predominately as females and juveniles who are emotionally and economically distressed, culturally alienated, and urbanite in origins, then what are the physical/material qualities that characterize contemporary displacement environments? A quick look at the largest/most populous refugee "complex" in the worldDadaab in remote northeastern Kenya-provides an image of an environment literally constructed of dirt and scavenged resources. The Dadaab complex holds a population of 290,000 Somalis on a $50 \mathrm{sq} \mathrm{km}$ area of land initially planned to hold 90,000 refugees. Over the past 20 years, people in the camp have fashioned an environment that is almost city-like, living in "the blocks - primitive communities of mud, twig and recycled tin” [6]. Dwellings occupied by $12+/$ - refugees are constructed with walls "built from gathered twigs or mud bricks, which are smothered in a layer of more mud and cow dung to aid waterproofing" [7]. Furnishings are constructed of "sculpted mud" built integral to the dwelling's floor and walls. As remarkable as these conditions may seem, the ad hoc refugee city made of mud is not a singular phenomenon. There is in fact a remarkable correlation between the location of major refugee populations and earth-built construction traditions globally (Figure 1).
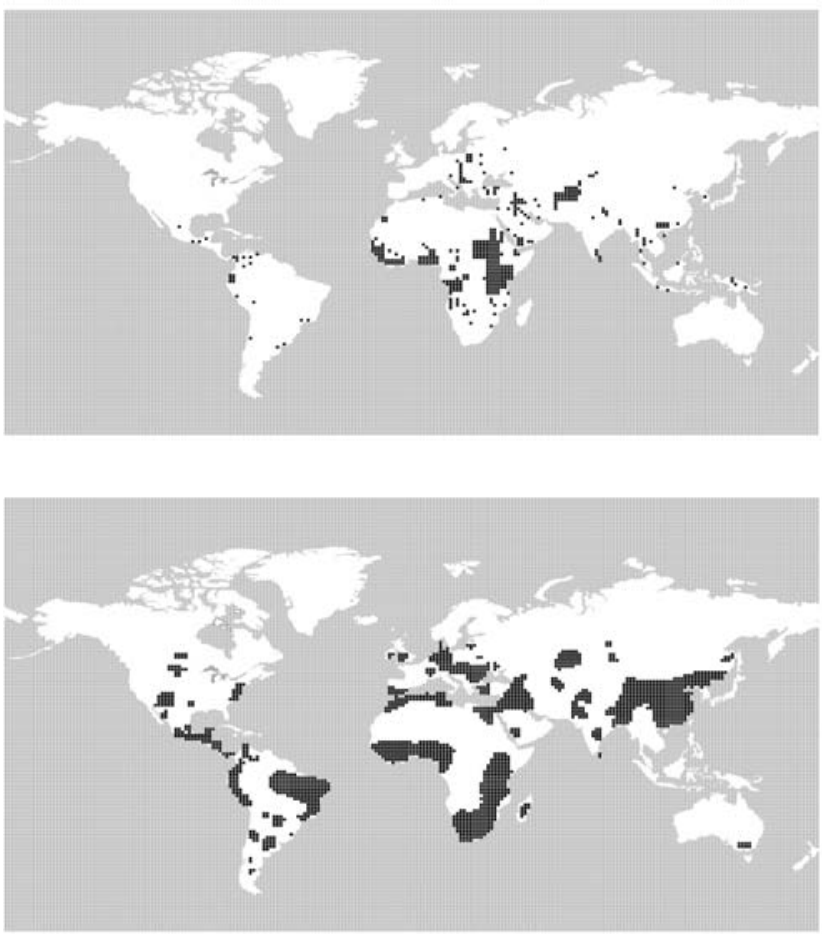

Fig. 1 Top Map - Major concentrations of refugees worldwide. Bottom Map - Earth built traditions globally.

Humanitarian construction technologies have attempted to capitalize on this material relationship in addressing refugee resettlement in the past. The manual block press (Figure 2), developed during the industrial age and "deployed" around the world by organizations such as the American Peace Corps, was [re]designed to assist in refugee resettlement and reconstruction, specifically in the form of mechanical mud-brick making. 


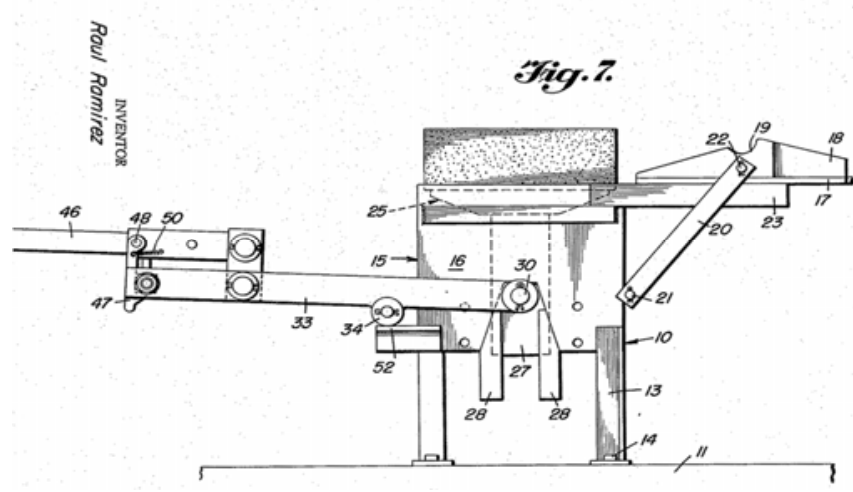

Fig. 2 U.S. Patent drawing 296278 depicts a leveraction Tectonic Machine that is technologically smart and relatively deployable/transportable.

The great advantage of this Industrial Age Tectonic Machine is that it permitted displaced populations to rebuild an architecture of their own making, and therefore one that was at least culturally familiar [8]. Refugees used the block press to make mud bricks, which are adaptable to a great variety of architectural forms: box-like dwellings, curvilinear dwellings, vaulted dwellings, etc., according to custom. Where this technology has begun to "fail" perhaps, is in the need to construct what author Jim Lewis calls the Exigent City [9], or the contemporary urban refugee city:

“...A kind of spontaneous urbanization that N.G.O.s simply don't know how to address. As of last year, 50 percent of the world lives in an urban area. [When we talk about refugees] we're no longer dealing with the idea of a small [rural/agrarian] village. We're dealing with a group of people who may be taxi drivers, who may be teachers, who may be government officials.”

"This has created an ongoing housing emergency: megaslums, shantytowns, favelas, squatter's colonies. There are 80,000 people living on top of a garbage dump in Manila; a population of indeterminate size - perhaps as many as a million - who sleep every night in the cemeteries of Cairo; homeless encampments in San Francisco, Atlanta and Houston; guest workers camped beside the towers of the Persian Gulf; migrant workers in the San Fernando Valley. They are all displaced people.”

So the task at hand for new developments in humanitarian construction technologies is in fact city making. If a team of seven well-nourished adult males can manufacture 500 mud blocks in a single day, it would still take quite some time and a lot of bricks to build an urban environment (the "structure" for supporting an urban micro economy) that would provide taxi drivers, teachers, and government officials with work. It would take even longer-or become simply impossible-to make an "emergency city" if the labor-intensive and calorie-hungry block presses were being operated by distressed and/or malnourished women and children. One technological detail worth noting about the refugees living in Dadaab; many of them own cell phones. That implies a developed network of communications for both humans and computational machines, and a potential for software transfer/acquisition.

\section{CITY-MAKING MACHINES}

Over the years ISARC Proceedings have published proposals for automated and/or robotic construction machinery intended for use in building megastructures, and/or constructing very large buildings quickly. As the data touched upon earlier in this writing describes a dire need for machines that can create urbanity out of dirt (Figure 3), the remainder of this paper will report on the development of a machine for forming/molding buildings, employing liquefied dirt/mud or a sun-fired/no-fire ceramic material.
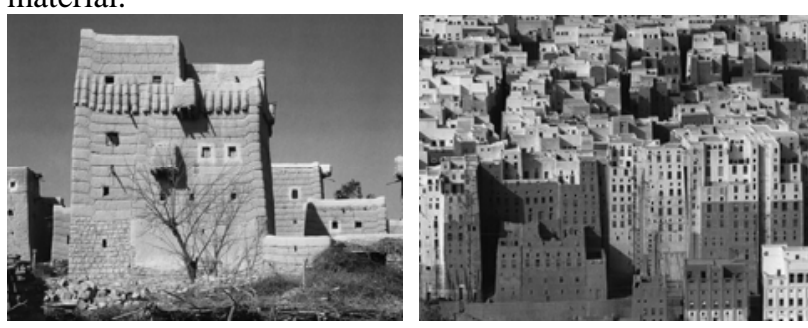

Fig. 3 Multi-storey urbanism made of dirt, Yemen. These buildings were formed using rammed-earth technology.

Information Age Tectonic Machines that are both transmitting and constructing systems might one day become as ubiquitous as helicopters and cargo planes when we speak about technological mediation in response to humanitarian crisis. While admiring the "mobility, 
immediacy, and adaptability" [10] of the block press as ideal, designing these new machines is also informed by crisis-shelter studies, and what author Ian Davis describes as the refugee's need for systems, not shelter [11]. We need to supply refugee populations with technologies that can aid rebuilding on their socio-cultural terms, rather than designing preconceived architectural "solutions" that are imposed. The "product" of these humanitarian systems must be adaptable—at the local level— to an extreme.

\section{PROJECT: MECHANICAL FORMWORK}

Four distinct models of Shokushu Machines have evolved from an essential concept of variable mechanized formwork that can be digitally configured on site or via remote transmission (Figure 4). While Shok-Mod 01 is a series of casting plates hinged together and driven by hand drills, Shok-Mods 05 and 07 have since evolved into linked cartridges driven by internal servomotors. One of the most significant challenges in the development of these machines has been containing poured materials in the cavity between moveable plates/carts. The flex gasket pictured in the image below (quarter-scale model) has been replaced by a hard plate gasket in the most recent modelShok-Mod 07CMB (Figure 5). In a series of tests using the working model pictured below, the machine was also

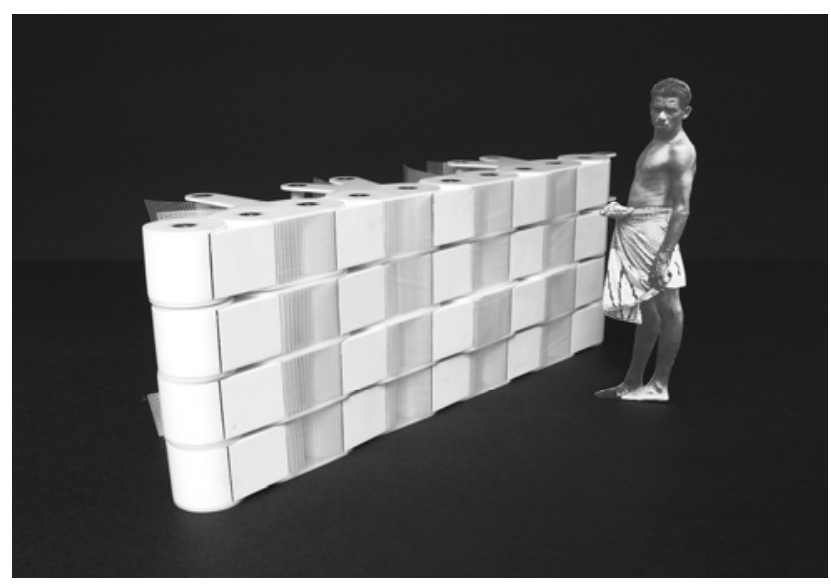

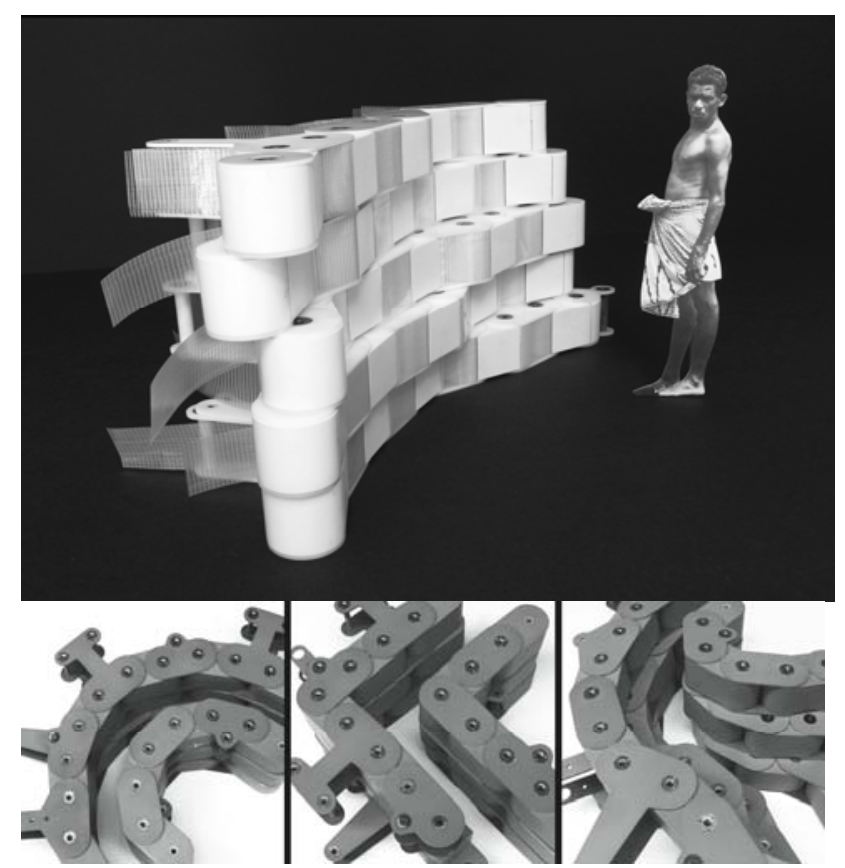

Fig. 4 Models of the Shok-Mod 05S depict a digitally controlled machine that can be configured as formwork for molding a variety of architectural forms or vernacular traditions (Note: opposing formwork removed for vis.).

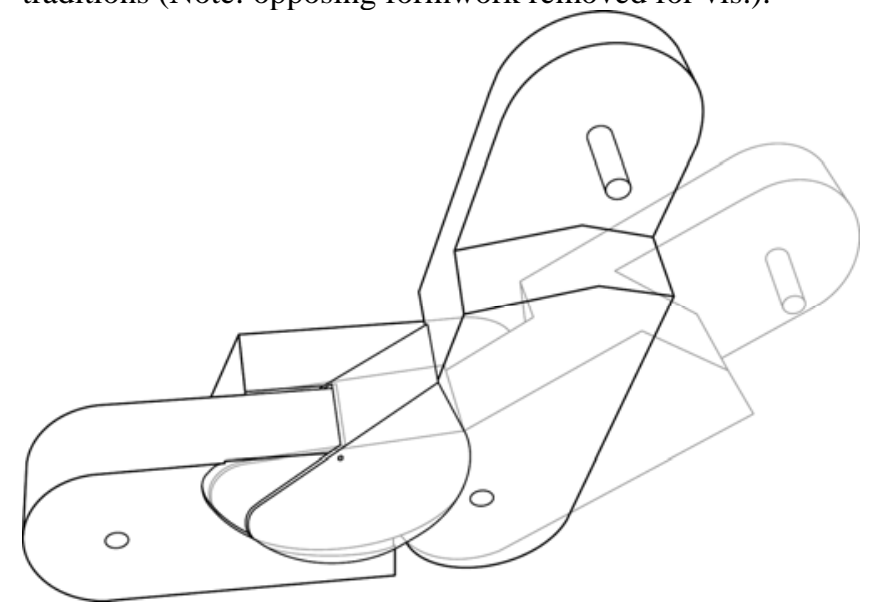

Fig. 5 A drawing of two linked Shok-Mod 07CMB “carts” with a sliding plate gasket covering the gap. 

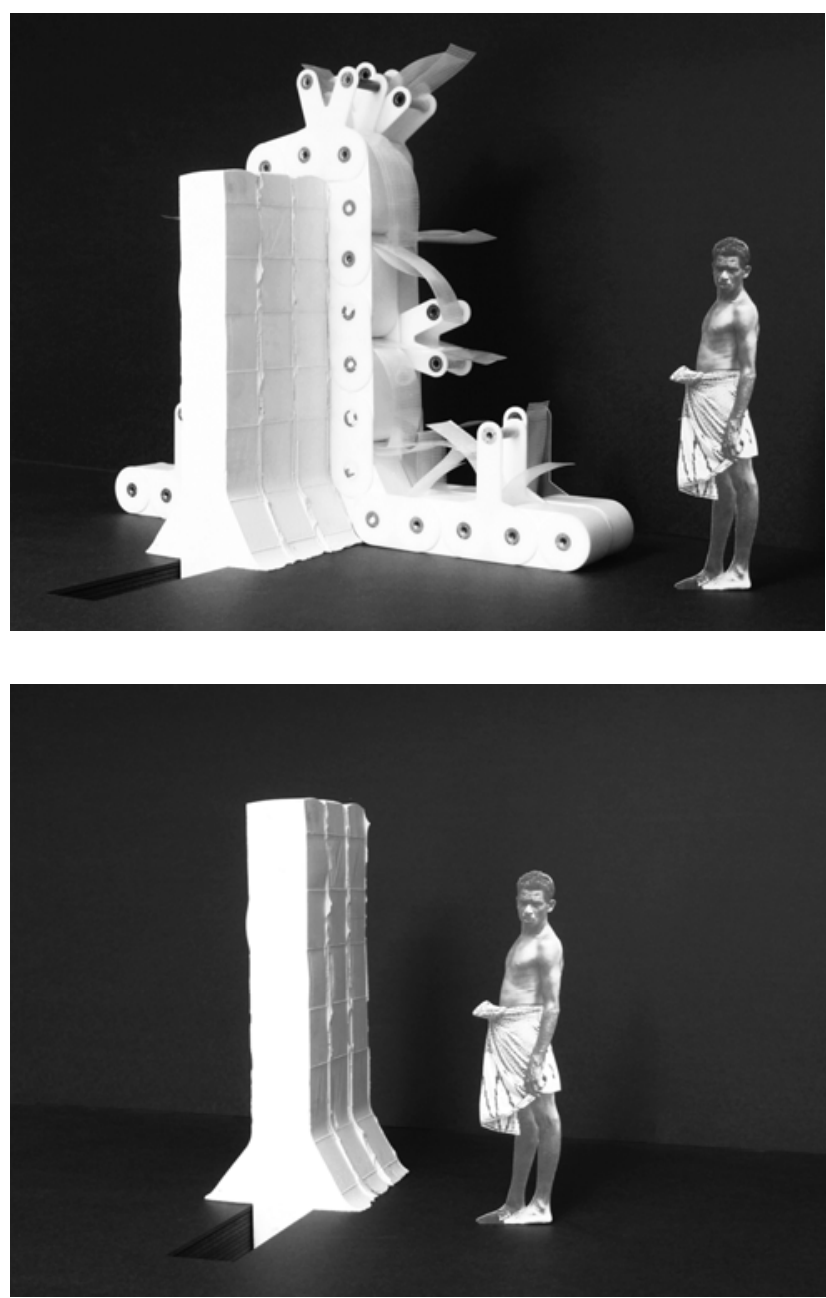

Fig. 6 Extruding a wall; architectural form-making using a working model of the Shok-Mod 05S

configured vertically in a manner that facilitates the extrusion of a wall (Figure 6), the most basic test of the machine's ability to make architecture.

\section{MANEUVERABILITY: CRAWLING \& WALKING}

Extrusion raises a number of issues related to maneuvering the machine. On the micro-level these machines will need to "crawl" and expand/contract in order to configure forms or extrude on uneven terrain, change cartridge orientation (horizontal/vertical), and "climb" in the manner of the conventional formwork we currently employ in constructing high-rise buildings (Figure 7). On the macrolevel, it is assumed that these machines would be loaded onto cargo planes and deployed to displaced populations in need. Future developments will allow highly mobile “walking” Tectonic Machines (Figure 8) to accompany migrating populations of refugees displaced by seasonal/ cyclical events such as monsoon, or shifting combat lines in prolonged military conflicts. Information Age Tectonic Machines "attached" to these populations will have the capability to scan or sense topography, as well recall/construct/transmit architectural specifics uniquely developed by/for the refugees.

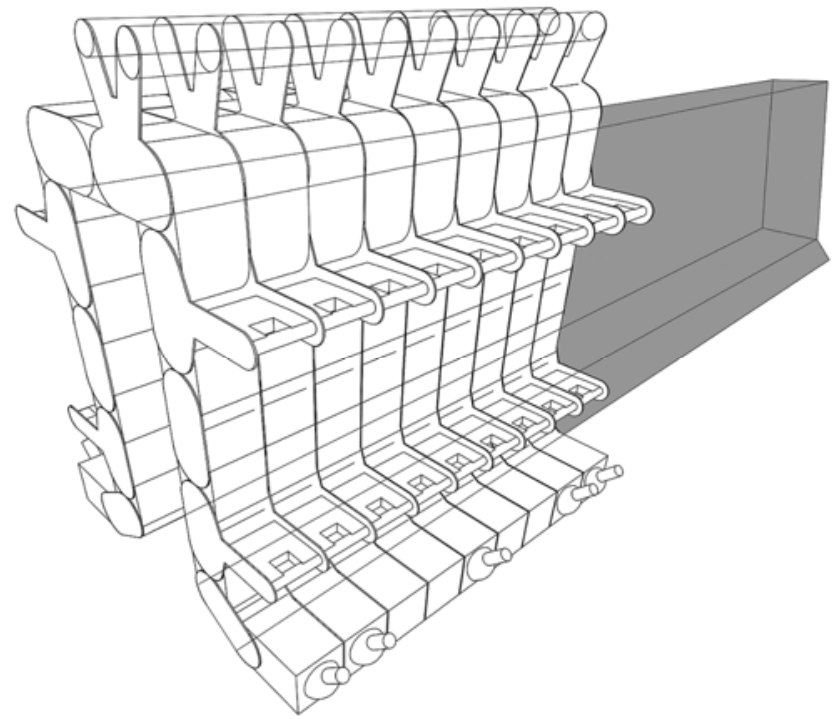

Fig. 7 Shok-Mod 05S configured to extrude. Crawling implements can be attached to the base of the machine. The variable capability of the machine aids motion stability.

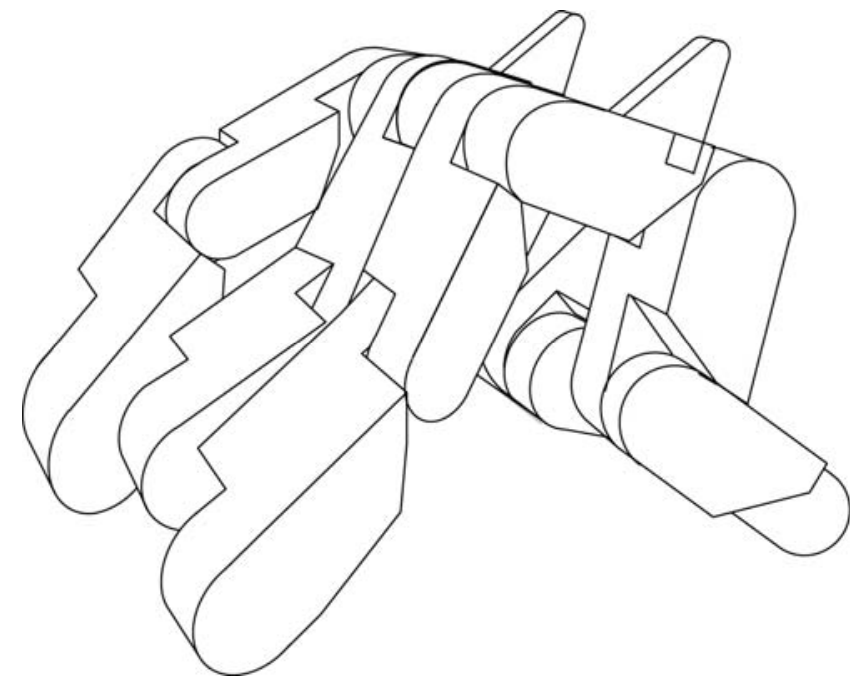

Fig. 8 Drawing depicting Shok-Mod 07CMB poised to walk. Inspired by recent developments in mechanical 
walking machines, including work by Theo Jansen (strandbeests) and Boston Dynamics (BigDog).

\section{FUTURE DEVELOPMENTS}

Addressing issues of movement control and formwork configuration has initiated a shift from scaled working models and renderings to full-scale servo-controlled prototypes. Associated research in materials testing, and continued fieldwork with refugees in long-term IDP camps in Sri Lanka \& Bangladesh will continue to inform the design and capabilities of the machinery.

Funding for this project was generously provided by Penn State's Hamer Center for Community Design: http://hamercenter.psu.edu/welcome

\section{REFERENCES}

[1] Bock, T., “Turning Points in Construction”, Proceedings, $26^{\text {th }}$ International Symposium on Automation and Robotics in Construction, Austin, Texas, 2009.

[2] "UNHCR Statistical Online Population Database, United Nations High Commissioner for Refugees (UNHCR), Data extracted: 08/03/2011" www.unhcr.org/statistics/populationdatabase

[3] McCleary, P., "Some Characteristics of A New Concept of Technology”, Journal of Architectural Education (1984-), Vol. 42, No. 1 (Autumn 1988), pp. 4-9 [4] "UNHCR Statistical Online Population Database, United Nations High Commissioner for Refugees (UNHCR), Data extracted: 08/03/2011" www.unhcr.org/statistics/populationdatabase

[5] ibid.

[6] Storr, W., "No Way Out: Inside the World's Biggest Refugee Camp”, The Independent, July 17, 201

[7] ibid.

[8] Asquith, L. \& Vellinga, M., eds. Vernacular Architecture in the Twenty-First Century: Theory, Education and Practice, Taylor \& Francis, London 2006, pp.13

[9] Lewis, J., "Phenomena-The Exigent City", The New York Times Magazine, June 8, 2008
[10] Shaffer, M. "Mobile, Immediate, and Adaptable (for the People): Three Attributes of Tectonic Machines in the New Mechanical Age” Chang[e]ing Identities: Design, Culture, + Technology, Proceedings from the 2009 Fall ACSA Regional Conference, ed. Dye, W.

[11] Davis, I., "Sheltering from Extreme Hazards", Vernacular Architecture in the Twenty-First Century: Theory, Education and Practice, Taylor \& Francis, London 2006, pp.145 - 154

\section{FIGURES}

Figure 1: Source materials for maps include:

http://millionsoulsaware.org/ and Atlas of Vernacular Architecture of the World, by Vellinga, Oliver, \& Bridge Figure 3: Images used for scholarship under the doctrine of fair use. Source: Steen, Athena, Bill Steen, Eiko Komatsu, and Yoshio Komatsu. Built by Hand: Vernacular Buildings Around the World. Salt Lake City, Utah: Gibbs Smith, 2003. 